\title{
Pengaruh Motivasi terhadap Peningkatan Produktivitas Kerja Karyawan pada PT. Bank Rakyat Indonesia (Persero) Cabang Makassar Ahmad Yani Unit Perintis Kemerdekaan
}

\author{
Nova Pratiwi*1 \\ A. Kartini Sari Putri D. ${ }^{2}$ \\ Fadlina $^{3}$ \\ 1,2Manajemen, Sekolah Tinggi Ilmu Ekonomi Ichsan Sidenreng Rappang, Indonesia \\ ${ }^{3}$ Program Studi Manajemen, Sekolah Tinggi Ilmu Ekonomi Ichsan Sidenreng Rappang, Indonesia \\ *e-mail: novapratiwi55@gmail.com ${ }^{1}$, aksputrid@gmail.com ${ }^{2}$, fadlinadamis22@gmail.com ${ }^{3}$
}

(Naskah masuk : tgl bln thn, Revisi : 1922 2021, Publikasi : 1201 2022)

\begin{abstract}
Abstrak
Penelitian ini bertujuan untuk menganalisis Pengaruh Motivasi terhadap Peningkatan Produktivitas Kerja Karyawan pada PT. Bank Rakyat Indonesia (Persero) Cabang Makassar Ahmad Yani Unit Perintis Kemerdekaan. Populasi pada penelitian ini adalah Karyawan pada PT. Bank Rakyat Indonesia (Persero) Cabang Makassar Ahmad Yani Unit Perintis Kemerdekaan. Penelitian ini menggunakan metode penelitian pustaka dan penelitian lapangan, sehingga diperoleh sampel sebanyak 5 periode dari tahun 2017-2021 dari seluruh total karyawan PT. Bank Rakyat Indonesia (Persero) Cabang Makassar Ahmad Yani Unit Perintis Kemerdekaan. Metode analisis yang digunakan adalah metode kuesioner dan metode observasi. Hasil Penelitian ini menyatakan Sistem pemberian motivasi yang diterapkan oleh PT. Bank Rakyat Indonesia Cabang Makassar Ahmad Yani Unit Perintis Kemerdekaan berupa: Motivasi langsung (Direct Motivation) Motivasi langsung merupakan motivasi yang berupa materi maupun non materi yang diberikan secara langsung kepada setiap karyawan untuk memenuhi kebutuhan serta kepuasannya. Jadi sifatnya khusus seperti bonus. Hasil penelitian diperoleh bahwa variabel pemberian motivasi yang dijadikan sebagai variable penting dalam meningkatkan produktivitas karyawan adalah bonus ini terlihat dari t-hitung lebih besar dari t-tabel $(5,992)$ yang lebih besar 3,182 sehingga bonus berpenagaruh secara signifikan terhadap produktifitas karyawan.
\end{abstract}

Kata kunci: Motivasi Ekstrinsik, Motivasi Intrinsik, Peningkatan Produktivitas

\begin{abstract}
This study aims to analyze the effect of motivation on increasing employee productivity at PT. Bank Rakyat Indonesia (Persero) Makassar Branch, Ahmad Yani, the Independence Pioneer Unit. The population in this study were employees at PT. Bank Rakyat Indonesia (Persero) Makassar Branch, Ahmad Yani, the Independence Pioneer Unit. This study uses library research and field research methods, so that a sample of 5 periods from 2017-2021 is obtained from all employees of PT. Bank Rakyat Indonesia (Persero) Makassar Branch Ahmad Yani of the Independence Pioneer Unit. The analytical method used is the questionnaire method and the observation method. The results of this study stated that the motivational system applied by PT. Bank Rakyat Indonesia Makassar Branch Ahmad Yani Independence Pioneer Unit in the form of: Direct Motivation Direct motivation is motivation in the form of material or non-material that is given directly to each employee to meet their needs and satisfaction. So it is special like a bonus. The results of the study show that the motivational variable that is used as an important variable in increasing employee productivity is that this bonus can be seen from the t-count which is greater than t-table (5.992) which is greater at 3.182 so that the bonus has a significant effect on productivity. employee.
\end{abstract}

Keywords: Motivation Ekstrinsik, Motivatin Instrinsik, Productivity Increase

\section{PENDAHULUAN}

Perkembangan dunia perbankan yang sangat pesat mengharuskan bank-bank yang ada mendapatkan sumberdaya manusia yang berkualitas, untuk menghasilkan sumberdaya manusia yang diharapkan tersebut salah satu caranya dapat dilakukan dengan memotivasi sumber daya manusia secara tepat. Produktivitas dimulai dari kebutuhan nasabah dan berakhir pada persepsi 
nasabah. Hal ini dapat diimplementasikan interaksi antara karyawan (pekerja) dan pelanggan yang mencakup:

(a) ketepatan waktu, berkaitan dengan kecepatan memberikan tanggapan terhadap keperluankeperluan nasabah;

(b) penampilan karyawan, berkaitan dengan kebersihan dan kecocokan dalam berpakaian;

(c) kesopanan dan tanggapan terhadap keluhan,

Berkaitan dengan bantuan yang diberikan dalam menyelesaikan masalah-masalah yang diajukan nasabah, Berarti produktivitas yang baik dilihat dari persepsi nasabah bukan dari persepsi perusahaan. Persepsi nasabah terhadap produktivitas jasa merupakan penilaian total atas kebutuhan suatu produk yang dapat berupa barang ataupun jasa. Untuk memotivasi sumberdaya manusia secara tepat digunakan motivasi dalam bentuk intrinsik yaitu pendorong kerja yang bersumber dari dalam diri pekerja sebagai individu, dan motivasi dalam bentuk ekstrinsik merupakan pendorong yang bersumber dari luar diri pekerja berupa suatu kondisi yang mengharuskannya melaksanakan pekerjaan secara maksimal.

Dalam penelitian ini penulis menfokuskan pada motivasi dalam bentuk ekstrinsik melalui pemberian bonus. Pemberian bonus yang diberikan kepada karyawan tetap merupakan pemotivasian kerja yang bersifat fleksibel dimana pemberian bonus yang diberikan oleh pihak perusahaan sifatnya tidak tetap dan dapat diberikan sewaktu-sewaktu yang dialokasikan melalui keuntungan perusahaan, sampai saat ini pemberian bonus merupakan program yang bersifat berkesinambungan dan system yang tepat dalam memotivasi karyawan. Produktivitas karyawan dapat dijadikan sebagai tolak ukur keberhasilan karyawan tersebut dalam melaksanakan tugas yang menjadi tanggung jawabnya, dan apabila sudah mulai dirasakan penurunan produktivitas, maka harus diupayakan untuk mencari faktor penyebabnya, selanjutnya dicarikan pemecahan masalahnya agar masalah tersebut tidak berlarut-larut dan menghambat pencapaian tujuan perusahan.

Oleh sebab itu, semakin tinggi produktivitas karyawan maka hasil kerjanya akan lebih efektif dan efisien, sebaliknya apabila produktivitas karyawan rendah, maka hasil kerjanya kurang menunjukkan efektivitas dan efisiensi. Sumber daya manusia menjadi aset utama pada sebuah perusahaan. Tercapainya tujuan perusahaan tergantung pada Produktivitas sumberdaya manusia di dalamnya. Produktivitas sumberdaya manusia ditentukan oleh motivasi kerja "daya pendorong" yang menimbulkan semangat kerja dan rasa tanggung jawab dalam melaksanakan tugas dan hal tersebut juga dapat meningkatkan produktivitas kerja karyawan. Berkaitan dengan uraian tersebut, maka penulis tertarik meneliti judul: "Pengaruh Motivasi terhadap Peningkatan Produktivitas Kerja Karyawan pada PT. Bank Rakyat Indonesia (Persero) Cabang Makassar Ahmad Yani Unit Perintis Kemerdekaan “.

\section{Tujuan Penelitian}

Untuk mengetahui pengaruh motivasi dalam bentuk ekstrinsik melalui pemberian bonus terhadap peningkatan produktivitas kerja karyawannya pada PT. Bank Rakyat Indonesia (persero) Cabang Makassar Ahmad Yani Unit Perintis Kemerdekaan.

\section{Kegunaan Penelitan}

Adapun kegunaan dari penelitian ini adalah sebagai berikut:

Sebagai bahan masukan bagi pimpinan pada PT. Bank Rakyat Indonesia dalam kaitannya dengan pemberian motivasi terhadap peningkatan produktivitas kerja karyawan di masa yang akan datang

1. Sebagai bahan referensi bagi para pihak-pihak yang ingin melakukan penelitian yang sama.

2. Sebagai bahan masukan bagi pimpinan pada PT. Bank Rakyat Indonesia dalam kaitannya dengan pemberian motivasi terhadap peningkatan produktivitas kerja karyawan di masa yang akan dating.

\section{Kerangka Pikir}

PT. Bank Rakyat Indonesia (persero) cabang Makassar Ahmad Yani Unit Perintis Kemerdekaan adalah salah satu bank yang dimiliki oleh pemerintah. Sumberdaya manusia menjadi aset utama dalam melakukan pencapaian tujuan bank yakni menghimpun dana sebesar- 
besarnya dari masysarakat. Untuk hal tersebut maka karyawan diberikan motivasi secara tepat, motivasi yang dimaksudkan yaitu motivasi dalam bentuk ekstrinsik melalui pemberian bonus. Dengan adanya pemberian motivasi ini diharapkan dapat meningkatkan produktivitas karyawan. Untuk lebih jelasnya dapat dilihat pada skema alur kerangka pikir.

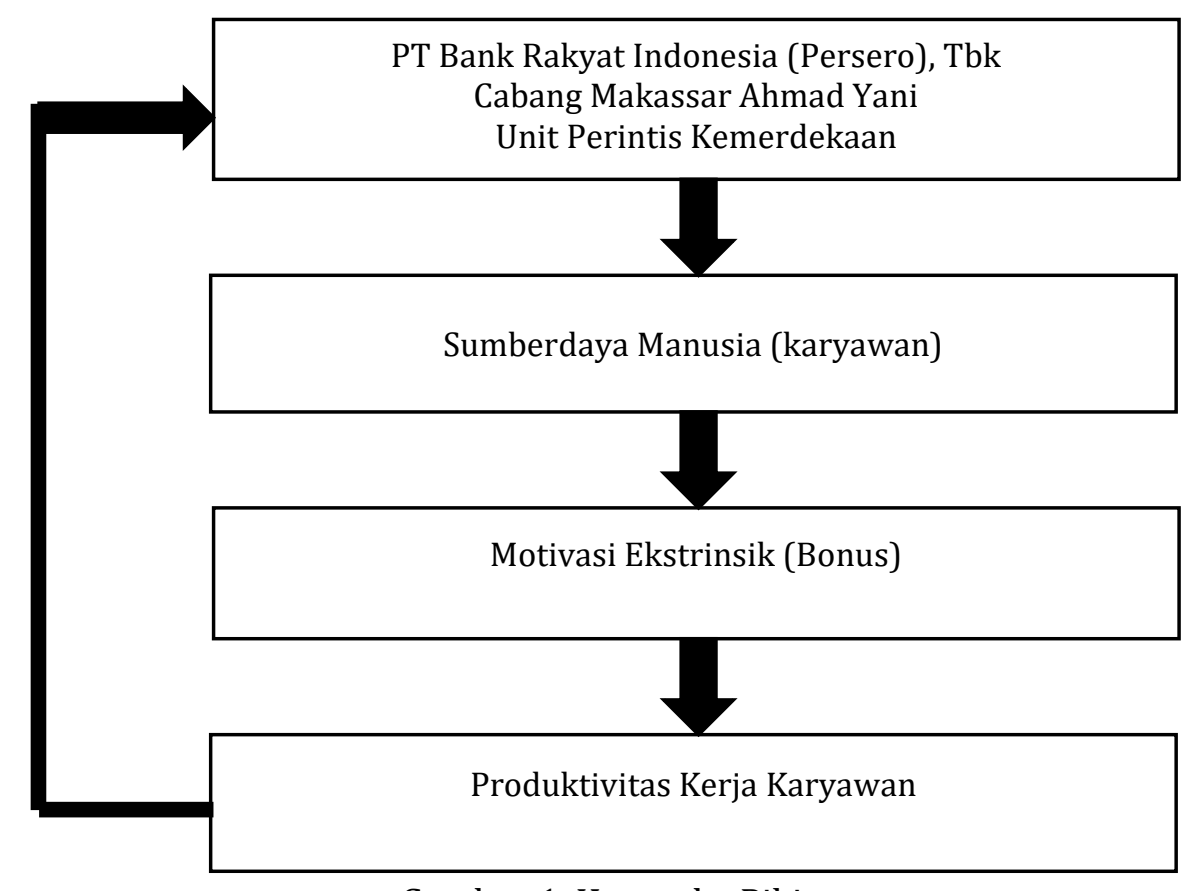

Gambar 1. Kerangka Pikir

\section{METODE}

Adapun perusahaan yang akan dijadikan obyek penelitian adalah Kantor Administrator Pelabuhan Makassar yang bertempat di Jalan Hatta No.2 Makassar. Penelitian dan penulisan sampai pada penyusunan laporan kurang lebih 2 (dua) bulan. Penelitian ini bertujuan untuk mengetahui pengaruh lingkungan kerja terhadap semangat dan kegairahan kerja studi pada karyawan kantor administrator. Dalam penelitian ini Laporan penelitian disusun dan diselesaikan dengan pedoman pada metode kasus, yaitu suatu metode bermaksud menerangkan obyek yang diteliti dengan mempergunakan data dari obyek yang diteliti itu sendiri.

Populasi dalam penelitian ini adalah seluruh karyawan pada Kantor Administrator Pelabuhan Makassar. Jumlah sampel dalam penelitian ini ditentukan sebanyak 60 orang. dalam penelitian ini adalah metode Accidental Sampling, yaitu sampel dipilih dengan cara memilih siapa saja yang ditemui saat itu, dalam hal ini adalah karyawan yang ditemui saat itu untuk menjawab kuisioner. analisis data yang digunakan untuk menguji untuk hipotesis yang telah diajukan dalam penelitian ini adalah metode Deskriptif Kualitatif dengan menggunakan kuisioner. Acuan pengukuran untuk mengukur tingkat kepuasan karyawan digunakan skala 5 tingkat (likert) dimana skala likert merupakan metode untuk pemberian ranking dan scoring ada kejadian, objek dan lain-lain secara relatif yang terdiri atas: Sangat Puas, Puas, cukup Puas, Tidak Puas, Sanga Tidak Puas.

Tabel 1. Penilaian Score Pernyataan

\begin{tabular}{ccc}
\hline Jenis Pernyataan & Jenis Jawaban & Score \\
\hline \multirow{4}{*}{ Positif } & Sangat Tidak Setuju (STS) & 1 \\
& Tidak Setuju (TS) & 2 \\
& Ragu-ragu (R) & 3 \\
& Setuju (S) & 4 \\
& Sangat Setuju (SS) & 5 \\
\hline
\end{tabular}




\section{Metode Pengumpulan Data}

1. Jenis Data

Dalam penelitian ini, jenis data yang digunakan adalah data kuantitatif. Data kuantitatif menurut Mudrajad kuncoro $(2009 ; 145)$ ialah data yang diukur dalam suatu skala numeric (angka)

2. Sumber Data

a. Data Primer

Data primer adalah data yang diperoleh secara langsung dari sumber asli (tanpa perantara). Data primer yang ada dalam penelitian ini merupakan hasil penyebaran kuesioner pada sampel yang telah ditentukan. Dari kuesioner tersebut akan didapat data mengenai bagaimana tanggapan responden mengenai variable-variabel yang ada dalam penelitian ini yaitu variable pengaruh motivasi(X1), sebagai factor- peningkatan produktivitas kerja karyawan (Y1).

b. Data Sekunder

Data sekunder adalah data yang diperoleh secara tidak langsung (ada perantara). Baik berupa keterangan maupun litelatur yang ada hubungannya dengan penelitian ini. Data yang digunakan dalam penelitian ini adalah data yang bersumber dari jurnal, artikel, internet, dan surat kabar, dan lain-lain.

3. Teknik Pengumpulan data

Teknik pengumpulan data yang dilakukan dalam penelitian ini adalah:

a. Penelitian lapangan (Field Research), Kuesioner merupakan teknik pengumpulan data yang dilakukan dengan cara menyusun pertanyaan-pertanyaan yang terdiri dari antara lain seputar data diri responden dimana dalam hal ini menggunakan skala nominal (nominal scale) yang menghasilkan jawaban berupa nama atau tanda dari sesuatu. Skala yang digunakan adalah skala interval (Interval Scale) yang dapat menghasilkan data yang memiliki rentang nilai dan menghasilkan pengukuran yang memungkinkan perhitungan statistik yang diperlukan saat pengolahan data.

b. Studi Kepustakaan

Merupakan pengumpulan data dengan tujuan untuk mengetahui berbagai pengetahuan atau teori-teori yang berhubungan dengan permasalahan penelitian, diantaranya berasal dari buku, majalah, jurnal, maupun berbagi litelatur yang relevan dengan penelitian ini.

\section{Uji Asumsi Klasik}

\section{Uji Normalitas}

Uji normalitas bertujuan untuk menguji apakah dalam model regresi, variabel pengganggu atau residual memiliki distribusi normal. Seperti diketahui bahwa uji t mengasumsikan bahwa nilai residual mengikuti distribusi normal. Kalau asumsi ini dilanggar maka uji statistik menjadi tidak valid untuk jumlah sampel kecil (Ghozali, 2011).

Uji normalitas yang digunakan dalam penelitian ini adalah uji statistik One Sample Kolmogorov-Smirnov Test. Dalam uji One Sample Kolmogorov-Smirnov Test, variabel-variabel yang mempunyai Asymp. Sig (2-tailed) di bawah tingkat signifikan sebesar 0,05 (probabilitas < 0,05 ) diartikan bahwa variabel-variabel tersebut memiliki distribusi tidak normal. Sebaliknya jika variabel-variabel yang mempunyai Asymp. Sig (2-tailed) di atas tingkat signifikan sebesar 0,05 (probabilitas $>0,05$ ) diartikan bahwa variabel-variabel tersebut memiliki distribusi normal.

2. Uji Multikolinieritas

Uji Multikolonieritas bertujuan untuk menguji apakah model regresi ditemukan adanya korelasi antar variabel bebas (independen). Model regresi yang baik seharusnya tidak terjadi korelasi diantara variabel independen. Jika variabel independen saling berkorelasi, maka variabel-variabel tidak ortogonal. Variabel ortogonal adalah variabel independen yang nilai korelasi antar sesama variabel independen sama dengan nol (Ghozali, 2011). Untuk mendeteksi bahwa ada tidaknya multikolinieritas di dalam regresi dapat dilihat dari: (1) tolerance value, (2) nilai variance inflation factor (VIF). Model regresi yang bebas multikolinieritas adalah yang mempunyai tolerance value di atas 0,1 atau VIF di bawah 10 (Ghozali, 2011). Apabila tolerance 
variance di bawah 0,1 atau VIF di atas 10 maka terjadi multikolinieritas.

3. Uji Heterokedastisitas

Uji Heteroskedastisitas bertujuan menguji apakah dalam model regresi terjadi ketidaksamaan variance dari residual satu pengamatan ke pengamatan lain. Jika variance dari residual satu pengamatan ke pengamatan lain tetap, maka disebut Homoskedastisitas dan jika berbeda disebut Heteroskedastisitas. Model regresi yang baik adalah yang Homoskedastisitas atau tidak terjadi Heteroskedastisitas (Ghozali, 2011).

Uji yang digunakan dalam penelitian ini adalah uji Glejser. Uji ini dilakukan dengan meregresi nilai absolut residual terhadap variabel independen. Jika variabel independen secara statistik berpengaruh signifikan terhadap variabel dependen maka terdapat indikasi terjadi Heteroskedastisitas dalam model regresi yang digunakan. Jika tidak ada satu pun variabel independen yang secara statistik berpengaruh signifikan terhadap variabel dependen maka tidak terjadi heteroskedastisitas dalam model regresi yang digunakan (Ghozali, 2011).

\section{Metode Analisis}

Dalam penelitian ini mempunyai tujuan untuk melihat pengaruh hubungan antara variabel independen terhadap variabel dependen dengan menggunakan analisis regresi linier berganda yang akan diolah menggunakan SPSS. Teknik analisis regresi linier berganda digunakan untuk mengetahui pengaruh variabel bebas (lingkungan kerja terhadap semangat kerja dan kegairahan kerja) secara parsial. Data yang dikumpulkan dalam penelitian ini diolah dan kemudian dianalisis dengan berbagai uji statistik sebagai berikut:

1. Analisis Statistik Deskriptif

Analisis statistik deskriptif memberikan gambaran atau deskripsi suatu data yang dilihat dari nilai rata-rata (mean), standar deviasi, varian, maksimum, minimum, sum, range, kurtosis, dan skewness (kemencengan distribusi). Hal ini perlu dilakukan untuk melihat gambaran keseluruhan dari sampel yang berhasil dikumpulkan dan memenuhi syarat untuk dijadikan sampel penelitian.

2. Analisis Regresi

Di dalam analisis regresi, selain mengukur kekuatan hubungan antara dua variabel atau lebih, juga menunjukkan arah hubungan antara variabel dependen dengan variabel independen. Variabel dependen diasumsikan random, yang berarti mempunyai distribusi probabilistik. Variabel independen diasumsikan memiliki nilai tetap (dalam pengambilan sampel yang berulang). Analisis yang digunakan dalam penelitian ini adalah analisis regresi berganda dengan melihat pengaruh antara status sosial orang tua, gaya hidup, dan pembelajaran diperguruan tinggi terhadap literasi keuangan. Perumusan model regresi yang digunakan adalah sebagai berikut:

$$
\mathrm{Y}=\mathrm{a}+\mathrm{b} 1 \mathrm{X} 1+\mathrm{e} 9
$$

Keterangan:

$\mathrm{Y}=$ Peningkatan Produktivitas karyawan

$\mathrm{a}=$ Konstanta

$\mathrm{b}=$ Koefisien regresi variabel independen

$\mathrm{X} 1$ = Motivasi

$\mathrm{e}=$ Error term

Uji Hipotesis

Hipotesis dalam penelitian ini yaitu lingkungan kerja terhadap semangat kerja dan kegairahaan kerja. Pengujian hipotesis menggunakan analisis regresi berganda. Analisis regresi berganda dapat diukur dari nilai koefisien determinasi, dan nilai stastistik $\mathrm{t}$.

1. Uji Koefisien Determinasi $\left(\mathrm{R}^{2}\right)$

Koefisien determinasi $\left(\mathrm{R}^{2}\right)$ mengukur seberapa jauh kemampuan model regresi dalam menerangkan variasi variabel dependen. Nilai koefisien determinasi adalah antara nol dan satu. Nilai $\mathrm{R}^{2}$ yang kecil berarti kemampuan variable independen dalam menjelaskan variasi variabel dependen amat terbatas. Nilai yang mendekati satu berarti variabel independen memberikan hampir semua informasi yang dibutuhkan untuk memprediksi variasi variable dependen. 
Kelemahan mendasar penggunaan koefisien determinasi adalah bias terhadap jumlah variabel independen yang dimasukkan ke dalam model. Setiap tambahan satu variabel independen, maka $\mathrm{R}^{2}$ pasti meningkat. Oleh karena itu, banyak peneliti menganjurkan untuk menggunakan nilai Adjusted $\mathrm{R}^{2}$ pada saat mengevaluasi mana model regresi terbaik. Tidak seperti $\mathrm{R}^{2}$, nilai Adjusted $\mathrm{R}^{2}$ dapat naik atau turun apabila satu variabel independen ditambahkan ke dalam model regresi.

3. Uji Parsial (Uji t)

Pengujian koefisien secara parsial adalah untuk mengetahui pengaruh masing-masing variabel independen secara parsial (sendiri) terhadap variabel dependennya. Proses pengujian menggunakan uji t (t-test), dengan rumus:

$$
t=\frac{\beta_{i}}{\operatorname{Se}(\beta i)}
$$

Selanjutnya untuk mengetahui apakah variabel independen (secara parsial) mempunyai pengaruh negatif secara nyata (signifikan) terhadap variabel dependen dilakukan dengan membandingkan nilai $t_{\text {hitung }}$ dengan nilai $t_{\text {tabel }}$ pada tingkat signifikan $(\alpha)$ dan derajat kebebasan (df) tertentu ( $\mathrm{df}=\mathrm{n}-\mathrm{k}-1)$. dengan ktriteria pengujian sebaga berikut:

- Jika $-t_{\text {tabel }} \leq t_{\text {hitung, }}$ maka $\mathrm{H}_{0}$ diterima dan $\mathrm{H}_{\mathrm{a}}$ ditolak (Uji pihak kiri)

- Jika $t_{\text {tabel }} \geq t_{\text {hitung, }}$ maka $\mathrm{H}_{0}$ diterima dan $\mathrm{H}_{\mathrm{a}}$ ditolak (Uji pihak kanan)

Bila $\mathrm{H}_{0}$ diterima maka dapat disimpulkan suatu yang berpengaruh tidak signifikan, sedangkan bila $\mathrm{H}_{0}$ ditolak artinya suatu berpengaruh signifikan.

\section{HASIL DAN PEMBAHASAN}

Bagian hasil penelitian memuat hasil analisis uji hipotesis yang dapat menyertakan tabel, grafik, Berdasarkan hasil penelitian diperoleh bahwa selama lima tahun 2017 2021 besarnya bonus yang dikeluarkan oleh perusahaan untuk keseluruhan karyawan adalah sebagai berikut:

Tabel 2. Perkembangan Bonus karyawan pada PT.Bank Rakyat Indonesia Cabang Makassar Ahmad Yani Unit Perintis Kemerdekaan Tahun 2017 - 2021

\begin{tabular}{ccc}
\hline Tahun & Bonus (Rp) & $\begin{array}{c}\text { Perkembangan } \\
\text { (\%) }\end{array}$ \\
\hline 2017 & 20.525 .000 & - \\
2018 & 23.500 .000 & 14,49 \\
2019 & 30.000 .000 & 27,65 \\
2020 & 32.400 .000 & 8,00 \\
2021 & 35.300 .000 & 8,90 \\
\hline
\end{tabular}

Berdasarkan tabel 2 dapat diperlihatkan besarnya bonus yang dikeluarkan perusahaan selama lima tahun terakhir (2002-2006) pada tahun 2002 bonus yang dikeluarkan hanya Rp.20.525.000,- kemudian mengalami peningkatan 14,49\% ditahun 2003 atau naik menjadi Rp.23.500.000,-. pada tahun 2004 bonus yang diberikan perusahaan mencapai Rp.30.000.000,-atau meningkat sebesar 27,65\%. pada tahun 2005 mengalami penurunan sebesar $8,00 \%$ dibandingkan dengan tahun sebelumnya sedangkan pada tahun 2006 perusahaan memberikan bonus kepada karyawan sebesar Rp.35.300.000,- atau terjadi peningkatan sebesar $8.90 \%$ atau per. pada pembahasan sebelumnya telah dijelaskan perkembangan rata-rata jumlah bonus karyawan pertahunnya sebesar 11.80 \% dimana bonus yang diberikan oleh PT. Bank Rakyat Indonesia (Persero), Tbk Cabang Ahmad Yani Unit Perintis Kemerdekaan kepada karyawannya sangat bervariasi sesuai dengan masa kerja dan jabatan karyawan tersebut. 
Tabel 3. Perkembangan karyawan pada PT.Bank Rakyat Indonesia Cabang Makassar Ahmad Yani Unit Perintis Kemerdekaan Tahun 2002 - 2006

\begin{tabular}{ccc}
\hline Tahun & $\begin{array}{c}\text { Jumlah } \\
\text { Karyawan }\end{array}$ & $\begin{array}{c}\text { Perkembangan } \\
(\%)\end{array}$ \\
\hline 2002 & 4 & - \\
2003 & 5 & 4,05 \\
2004 & 5 & 5,05 \\
2005 & 6 & 5,06 \\
2006 & 6 & 6,06 \\
Total & 26 & $\bar{x} 20,22$ \\
\hline
\end{tabular}

Berdasarkan tabel 3 nampak komposisi karyawan pada PT. Bank rakyat indonesia cabang makassar ahmad yani unit perintis kemerdekaan selama lima tahun yaitu tahun 2002 sebanyak 4 orang, selanjutnya pada tahun 2003 dan 2004 sebanyak 5 orang terjadi penambahan 1 , sedangkan pada tahun 2005 - 2006 kembali terjadi penambahan karyawan sebanyak 1 orang sehingga jumlah akhir karyawan sampai tahun 2006 sebayak 6 orang, sehingga perkembangan karyawan dalam posentase rata-rata yaitu $20,22 \%$.

Dalam hubungannya dengan tabel 2 dan 3, maka besarnya produktivitas karyawan selama tahun 2002-2003 dapat ditentukan sebagai berikut :

$$
\begin{aligned}
& 2017=\frac{183.573 .000}{4}=45.893 .250 \\
& 2018=\frac{258.832 .000}{5}=51.766 .400 \\
& 2019=\frac{293.721 .000}{5}=58.744 .200 \\
& 2020=\frac{360.872 .000}{6}=60.145 .333,33 \\
& 2021=\frac{399.745 .000}{6}=66.624 .166,67
\end{aligned}
$$

Perhitungan produktivitas karyawan selama tahun 2017-2021 menunjukkan peningkatan yang berfluktuasi setiap tahunnya.Hal ini disebabkan karena presentase peningkatan pendapatan lebih besar dibandingkan dengan presentase peningkatan jumlah karyawan.

Tabel 4. Produktivitas kerja karyawan PT.Bank Rakyat Indonesia Cabang Ahmad Yani Unit Perintis Kemerdekaan tahun $2002-2006$

\begin{tabular}{cccc}
\hline Tahun & Pendapatan & \multicolumn{2}{c}{ Perkembangan } \\
& & Rupiah & (\%) \\
\hline 2002 & 45.893 .250 & - & - \\
2003 & 51.766 .400 & 5.873 .150 & 12,79 \\
2004 & 58.744 .200 & 6.977 .800 & 13,47 \\
2005 & $60.145 .333,33$ & $140.133,33$ & 0,23 \\
2006 & $66.624 .166,67$ & $6.478 .833,34$ & 10,77 \\
\hline
\end{tabular}


Presentase peningkatan produktivitas karyawan terbesar terjadi pada tahun 2004 yaitu 13,47 \% dengan nilai produktivitas sebesar Rp. 58.744.200 sedangkan persentase terkecil bahkan terjadi penurunan pada tahun 2005 yaitu $0,23 \%$

Tabel 5. Data untuk perhitungan Regresi sederhana

\begin{tabular}{ccc}
\hline Tahun & Produktivitas & Bonus \\
\hline 2002 & 45.893 .250 & 20.525 .000 \\
2003 & 51.766 .400 & 23.500 .000 \\
2004 & 58.744 .200 & 30.000 .000 \\
2005 & $60.145 .333,33$ & 32.400 .000 \\
2006 & $66.624 .166,67$ & 35.300 .000 \\
\hline
\end{tabular}

Tabel 6. Hasil Persamaan Regresi sederhana

\begin{tabular}{ccccc}
\hline $\begin{array}{c}\text { Variabel } \\
\text { bebas }\end{array}$ & $\begin{array}{c}\text { Koefisien } \\
\text { Regresi }\end{array}$ & t-hitung & t-tabel & Signifikan \\
\hline $\begin{array}{c}\text { Produktivitas } \\
\text { Bonus }\end{array}$ & $\begin{array}{c}20353518,169 \\
1,280\end{array}$ & 5,992 & 3,182 & 0,009 \\
\hline
\end{tabular}

Multiple $\mathrm{R}=0,988$

R square $\quad=0,975$

F- ratio $\quad=118,413$

Berdasarkan tabel 6 diperoleh persamaan Regresi Sederhana sebagai berikut : Y = $20353518,169+1,280$ X. Dari persamaan diatas maka dapat di interprestasikan adalah sebagai berikut $: \mathrm{b}=20353518,169$. Artinya apabila bonus dinaikkan satu rupiah, maka diharapkan produktivitas karyawan meningkat sebesar 20353518,169. a = 1,280 merupakan nilai konstanta atau reciprocal artinya apabila bonus tidak mengalami perubahan maka produktivitas karyawan sebesar 1,280.

Kemudian untuk mengetahui keeratan pengaruh atau hubungan bonus dengan produktivitas karyawan dapat dilihat dari besarnya nilai koefisien korelasi (R). Hasil perhitungan menunjukkan besarnya nilai koefisien korelasi sebesar 0,988 . hal ini menunjukkan adanya pengaruh yang sangat kuat antara bonus dengan produktivitas karyawan.

Selanjutnya untuk mengetahui besarnya pengaruh (kontribusi) Bonus terhadap Produktivitas karyawan dapat dilihat dari besarnya koefisien determinasi (R).Hasil perhitungan diperoleh nilai koefisien determinasi sebesar 0,975 yang artinya variasi naik turunnya produktivitas karyawan ditentukan oleh pemberian bonus sebesar 0,975 atau 97,5\% sedangkan sisanya 2,5\% dipengaruhi oleh faktor lain yang tidak diteliti.

Kemudian untuk membuktikan hipotesis dalam penelitian maka dilakukan uji t dengan langkah-langkah sebagai berikut :

$\mathrm{H} 0: \beta=0$ (tidak ada pengaruh antara bonus dengan produktivitas karyawan )

$\mathrm{H} 0: \beta \neq 0$ (ada pengaruh antara bonus dengan produktivitas karyawan)

a. Level of convidence $=95 \%$ atau $X=0,05$

b. $\quad$ d $. f=(n-k)=5-2=3$

c. t-hitung $=5,992 \mathrm{t}$-tabel $=3,182$

Oleh karena t-hitung lebih besar dari pada t-tabel $(5,992)$ lebih besar 3,182 sehingga pengaruh bonus dalam peningkatan produktivitas karyawan sangat signifikan maka dikatakan bahwa hipotesis yang menyatakan ada pengaruh antara pemberian bonus dengan produktivitas karyawan dapat diterima.

\section{KESIMPULAN}

Berdasarkan hasil pembahasan yang telah diuraikan pada bab sebelumnya maka dapat ditarik beberapa kesimpulan bahwa, sistem pemberian motivasi yang diterapkan oleh PT. Bank Rakyat Indonesia Cabang Makassar Ahmad Yani Unit Perintis Kemerdekaan berupa : 
Motivasi langsung (Direct Motivation). Motivasi langsung merupakan motivasi yang berupa materi maupun non materi yang diberikan secara langsung kepada setiap karyawanuntuk memenuhi kebutuhanserta kepuasannya. Jadi sifatnya khusus seperti bonus. Hasil penelitian diperoleh bahwa variabel pemberian motivasi yang dijadikan sebagai variable penting dalam meningkatkan produktivitas karyawan adalah bonus ini terlihat dari t-hitung lebih besar dari ttabel $(5,992)$ yang lebih besar 3,182 sehingga bonus berpenagaruh secara signifikan terhadap produktifitas karyawan.

Dalam hal pemberian bonus karyawan dalam upaya peningkatan produktivitas perusahaan diharapkan pihak perusahaan dapat lebih transparan mengenai alokasi dana bonus yang diterapkan pada PT. Bank Rakyat Indonesia Cabang Makassar Ahmad Yani Unit Perintis Kemerdekaan. Berdasarkan hasil perhitungan melalui uji parsial (uji - t) diperoleh bahwa faktor yang dominan mempengaruhi produktivitas karyawan adalah bonus dengan nilai t hitung lebih besar dari t tabel. berdasarkan simpulan diatas, sehingga saya menyarankan agar bonus pada PT. Bank Rakyat Indonesia Cabang Makassar Ahmad Yani Unit Perintis Kemerdekaan agar tetap dipertahankan dan ditingkatkan

\section{DAFTAR PUSTAKA}

Djafar, \& Syamsuddin, E. K. (2001). Statistik I \& II, penerbit Yayasan Pembangunan Kawasan Timur Indonesia.

Gomes, Cardosos, \& Faustino, (2003). Manajemen Sumber Daya Manusia, Andi, Yogyakarta.

Hasimbuan, \& Malayu, S. P. (2002). MSDM, edisi revisi, Bumi Aksara Jakarta

Hasimbuan, (2004). Dasar - Dasar Perbankan, Cetakan ketiga, Penerbit, Bumi Aksara, Jakarta.

Heidjrachaman, \& Suad, H. (1998). Manajemen Personalia, Edisi 4, penerbit BPFE yogyakarta

Kasmir, (2002). Manajemen Perbankan, PT. Ghalia Indonesia, Anggota IKAPI Jakarta.

Kosasih, K. (2020). Pengaruh Motivasi terhadap Kinerja Karyawan pada PT. Karunia Prima Sejati, Bandung.

Kurniawan, Y. I., Soviana, E., \& Yuliana, I. (2018). Merging Pearson Correlation and TAN-ELR algorithm in recommender system. AIP Conference Proceedings, 1977. https://doi.org/10.1063/1.5042998

Manulang, M. (2002) Manajemen Personalia, Balai Pustaka, Jakarta.

Martoyo, \& Susilo, (2002). Sumber Daya Manusia dan Produktivitas Kerja. Cetakan kelima, Bina Aksara, Bandung.

Moekijat, (1999). Manajemen Sumber Daya Manusia, cetakan 8 penerbit CV Mandar Maju, Bandung.

Nawawi, \& Handari, (2001). Perencanaan Sumber Daya Manusia, cetakan I, Penerbit Gajah Mada University Press, Yogyakarta

Nitisemito, \& Alex, S. (1998). Manajemen Personalia, edsi 1, Ghalai, Indonesia, Jakarta.

Nur, A. K., Idayanti, F., \& Umar, (2018). "Pengaruh masa kerja, pelatihan dan motivasi terhadap Produktivitas Kerja Karyawan PT. Bank SULSELBAR cabang utama Makassar". Jurnal Magister Manajemen Fakultas Ekonomi dan Bisnis vol.1 no.4 ISSN 192-211.

Nurjaya, N., Sunarsi, D., Effendy, A. A., Teriyan, A., \& Gunartin, G. (2021). Pengaruh Etos Kerja dan Disiplin Kerja terhadap Kinerja Pegawai pada Dinas Kehutanan dan Perkebunan Kota Bogor.

Ravianto, J. (1998). Produktivitas dan Pengukurannya, Seri Produktivitas VIII, PT. Binama Teknika, Jakarta.

Saljunuddin, M. L. (2018). "Pengaruh dan Penagalaman kerja terhadap produktivitas kerja karyawan PT. Comindo Mitra Sulawesi Cabang Palopo".

Sastrohadiwaryo, \& Siswanto, (2001). Manajemen Tenaga Kerja Indonesia. Bumi Aksara, Jakarta. 
Suwanto, S. (2019). Pengaruh Disiplin Kerja dan Motivasi Kerja terhadap Kinerja Karyawan pada Rumah Sakit Umum Tangerang Selatan.

Suwanto, S. (2019). Pengaruh Gaya Kepemimpinan dan Lingkungan Kerja terhadap Kinerja Karyawan unit telesales pada PT BFI Finance Indonesia Tbk.

Yusuf, \& Burhanuddin, (2019). "Manajemen Sumber Daya Manusia di Lembaga Keuangan Syariah". Jakarta: Rajawali Pers 